\title{
Discourse Act Contributing to the Linguistic Formulation from Word to Sentence: Albanian Children
}

\author{
Dr. Zamira Shkreli \\ Dr. Karmen Lazri
}

\section{Abstract}

In this argument, based in concrete observation for toddlers 2-4 years old, will be treated the case of lexical input of this age, used in the act of speech from the communication through special words- accompanied with extralinguistic means,- from holophrases, to generating simple sentences, as special constructs of syntax. Primal phases of owning the language have already slowly started in the first years of their lives. The child follows the unstoppable road to understanding and enriching knowledge. As helping to our material will be included, except for their group and family life, didactic materials as well, in which part of our study were "Open and Find out" books, which are made of secret windows and puzzle books, which contain plenty of material that serves to the children's speech-gaining act. The theory treating of the problem above will be mostly supported by Albanian language data, or by Albanian children - as native speakers of that mother language. The principal phases of owning the language have slowly started during the first years of his life. Now the child follows the unstoppable way to gaining and enriching his knowledge. The methodology followed in this material includes preschool children. During this phase the child articulates more lexical words than grammatical words. We noticed the phenomena when observing 14 children, who were selected from two age groups. The conversations of the different aged and gendered subjects were analyzed, as well as the vocabularies they owned. During this treatment will be shown linguistic features that children are prone to change from one phase of life to another. It's also interesting to emphasize how even in the word and sentence producing phase, children are developed and skilled by using didactic books on them.

Keywords: discourse act, linguistic formulation, word, sentence

\section{Introduction}

Several scholars have pointed out than by the age of one to two years, the child continues to remain closely dependent on effective plan, by his mother, he likes to be 
with her, to tell her everything he does, have her admiration, he makes it to participate in all its joys and sorrows [1].

Among that we can mention Marilyn Shatz, writing in terms of shaping and enriching the vocabulary, that first of all there is an explosion of a large number of names by the child because philosophical view, recognition starts from labeling objects. She states that the applicants and parents have note that some children once discover that things have a name and try to label them [2]...

Also, Genter (1982) suspects that the nouns prevail over verbs, because most of them refer to the first objects and are easily recognized; while verbs are supposed to be understood as words than can define the connection between objects and the object itself; as a result, cognition must be easier to give nouns a meaning. For example, in animal world, the youngest label initially: dog, cat, airplane, which designate the basic level categories; after this they use examples of more general level.

It is noted that this phenomena can be explained by the large noun classification category, for example: over generalized nouns, generalized nouns and specific nouns and emphasizing knowledge of the world around them, children pass naturally to those which are called specific names, according to the following scheme [3].From this text we have the explanation: The difference between iperonimeve and generalized noun is that the first, as much as they are equipped with the general meaning, however, have semantic spaces to describe. For example If we want to put under the above scheme, nouns, leopard, elephant, shark, animals, zebra, lion, deer, giraffe, orangutan, sheep, wolf, jackal, fox,... do the concepts explained above: if we start the noun of animals, dividing the herbivores and carnivores.

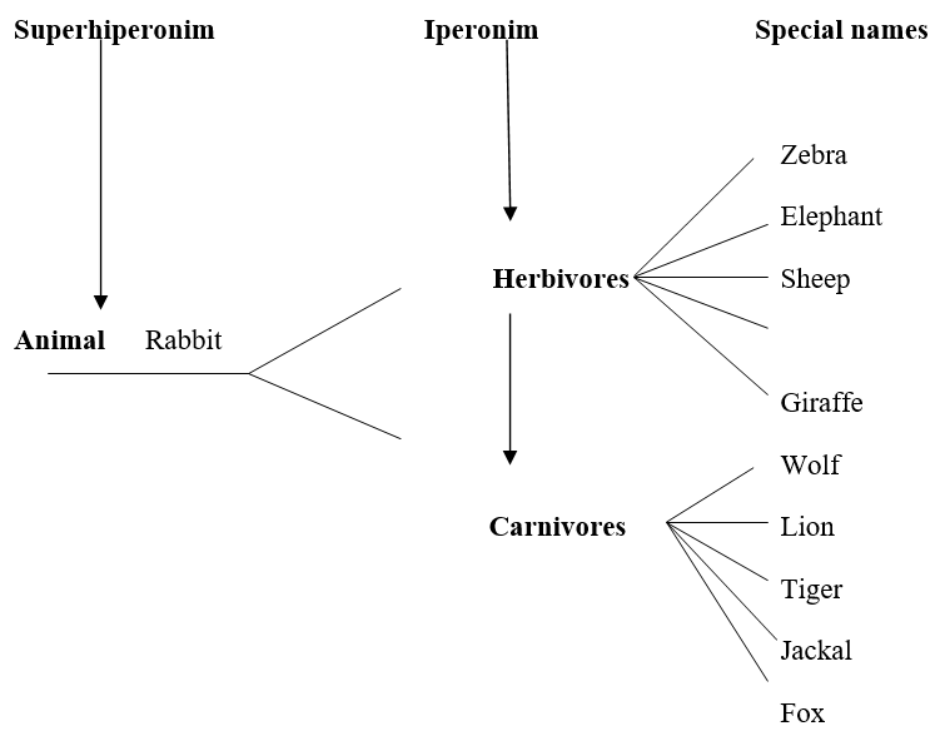


On the basis of this presentation generalized names (superhiperonime), hiperonime and specific names etc., exercises may be done, in which we on the one hand present mixed animal figures (carnivorous and herbivorous), connect them to a hay stack and a piece of hanging flesh; a very lexically benefiting physical and mental activity. So these exercises and preschool books that suit certain ages, help children grow rich linguistically. Didactic work that was attended by children of this age was to confront them with three types of didactic titles suitable to that age, through which the young are developed physically as well as linguistically. The first titles work with image formation puzzles. So, puzzle books help children to enrich their vocabularies. They get acquainted with figures of the world of animals which is very popular to children.

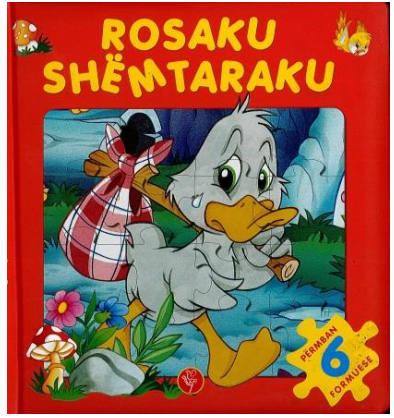

Illustrated books always arouse special interest in children moreover those aged 1-3 years old. Also the animal characters of these books are children's best friends. Actions that appear in the illustrations ensure the growth of mental and bodily development. They become capable to undertake the responsibilities of their age. Researcher R.H. Largo states: "A feature of child language development is they often broaden the real meaning of a word. For example by the word "cow" he names all bigger animals, not only cows but horses, goats and sheep as well. The child doesn't have only the tendency to expand the meaning of words. He can also restrict it. For example the word "car" applies only to the family car and not other cars. Even toy cars or illustrated cars aren't considered cars to him. So the word "car" is basically the name of the family car [4]."1
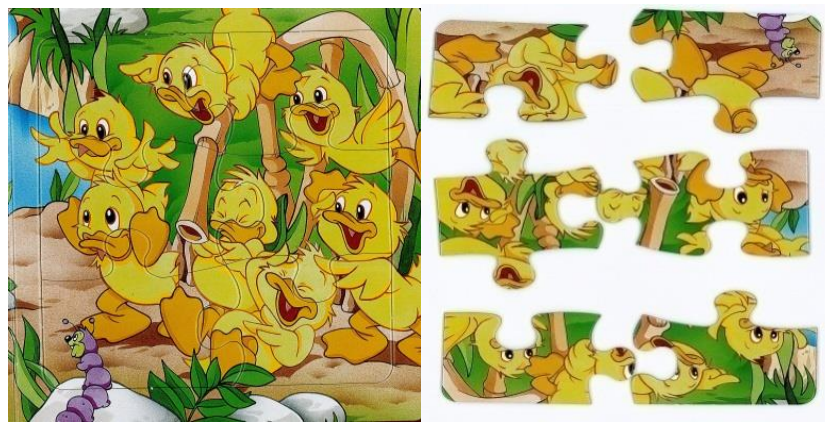
At first we describe the first book illustration which is in the child's hands. The way he manages to maneuver the particles of the image to create a full and clear illustration. The first part includes these extract elements: Duck, - water,-5 ducklings,- puzzle. Thus, children acquire the above words by repeating puzzle formation several times. While the second didactic material used by us in this essay are book with "Open the window and discover" illustrations, in which there are questions and answers which provide material to the toddler regarding to farm animals and their life and gestures they perform, such as the turkey's gllu-gllu"; so children become capable of finding differences of these similar looking birds. On the other side of the figure are questions such as "Who sleeps in a nest? Who sleeps in a cottage?" (Note that in a linguistic point of view, the pronoun "who" is only used to humans not animals or objects. We didn't change it to keep the citations.) Open the window and see the rabbit and the chicken. Two characters which are very familiar to children's life and games. Through these materials centered to figures which give the right messages to infants for their age, we keep in consideration that these figures perceive the right words to children. Two successive figures of our books familiarize the toddler to other farm animals. The following questions: "Who stays in a barn? Who stays in the meadow?" are rightly answered once the toddler opens the window and sees two other animals, the pig and the lamb. Another element that would encourage the toddler to think is the question: "Which is the difference between the goose and the duck?" The figure makes clear the obvious answer. "The goose is white." So we are dealing the thought-expansion, but also linguistic development, so that children enlarge their sentences, transforming them from one-worded sentences to multi-worded sentences such as: "Chicken sit on the roost.

Cocks go gllu-gllu.

Birds go tweet-tweet.
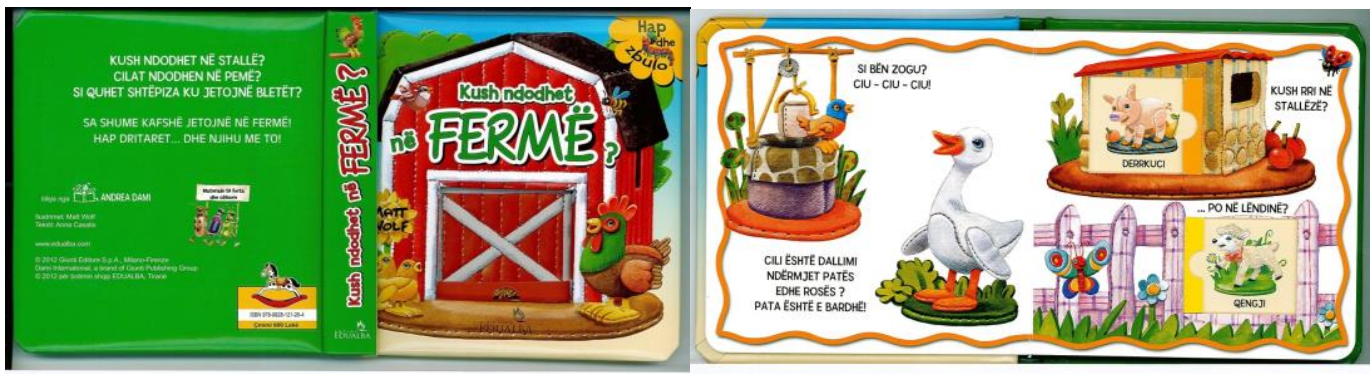

Other images displayed in front of each other provide the toddler with the necessary material about farm animals with gestures and actions they must perform like the "gllu-gllu" sounds of the turkey. So children become capable of finding differences in look-alike birds. One the other side of the figure stand questions such as "Who stays in a nest? Who stays in a roost?" You open the window and find "rabbit" and the "chicken", two characters well-known by the children that are part of their life and 
childish games. Through these materials which have in the center figures that give appropriate messages for the age we are considering for the fact that these children through the figures perceive the appropriate word for each picture of the book.

With the growth of the baby, the length of his sentences grows and this element is exactly a good indicator of syntactic development, with other words, the movement of the sentence in another state in quantity, also in quality. In his study "A language acquisition", he presented for the first time such an index for measuring the length of expressions called MLU [7]. MLU is based on the average length of sentences produced by the child, taken under study in spontaneous speech. This length is determined by the number of smaller and meaningful units that are Syntagma. Adding any of them, marks an increase of syntactic ability of the child. Children who have the same MLU have the same level of syntactic development and the same level of linguistic complexity. According to R Brown, to measure a child's MLU you should make at least a half-hour conversation with him or her. Brown accompanied the MLU concept with a set of rules for the calculation of the lexeme, among which we can mention the following:

Counted as a single lexeme

- Composite -word

- Impersonal nouns

- Irregular verbs in the past, as there is no evidence that the child connects this shape with its corresponsive in the present

- Auxiliary verbs and modals: have, be, could, should,

- Positive and negative particles: yes, no

- Flattering or reduced forms of names because for the child this is seen as a standard form

- Counted as two lexeme

- Names in gender crumples

- Plural names

- Regular verbs in the past

- Verbs in gerundive

- Not taken into shouts of type: em, eh, oh, etc.

- Should be analyzed at least 100 phrases spoken by the child.

Usually this stage begins about age 12-26 months and most are two-word sentences, although there are cases of sentences with three words or four.The interest of the child to discussions grows and he starts to listen attentively when his parents and sisters talk to each other. As the main quality of this stage is the use of words such as content: names, verbs, adjectives and lack of service words as hub words, plural endings, prepositions etc. This indicates that the child is not copying adults. In the sentence "Agron drink water", articulated by the child, it understands that the child manages to distinguish at least two classes of words. He distinguishes names: 
"Agron", "water" from the verb "drink". This is shown by the fact that it adjusts the verb with the subject "Agron".

This does not mean that they can't create group of words built by their rules, which leads to unusual results. "Agron eat" or "Agron eat bread". This phenomenon is related to initial difficulties and errors such children adjust quickly. Unusual formations of sentences show that the child does not receive language through imitation but through the structure of the rules [4].

Since its beginnings, the language is deeply creative which means that many of these sentences are never produced by adults. By increasing the complexity of expressions it's added even the usage of service words. A conjecture on this issue was raised by R.Miller [5], which stated that the children make that choice because these words (content words) are more pronounced and more frequent in the speech of adults and therefore are noticed more.

Knowledge of child syntax are based on what children themselves say, so above their speech. To achieve this level of knowledge, linguists have long studies based on listening to children when they play with each other, with older people, in experiments or through direct interviews. This is achieved through spontaneous speech of the child but anyway, even though it may be a set of data, many remain without being taught, by the fact that the linguist fails to understand fully what the child knows, as many of them can't have had the opportunity to express or use. Linguists psychologists give a firsthand important syntactic studies: the way how the young kids reach from the word - a group of words or to the sentence, which is equal to the full communication.

Double word phase expressions (holophrases)

About the 60s under the influence of linguistic vision of Chomsky, linguists assumed that the language of the child starts when the combine begins to merge the words or morpheme. This stage is the stage of double word expressions and was described by Bloom

"... Perhaps the most contested issue in linguistic studies ..." [6]

Ability to analyze and to create sentences appears to child in different ways. Some children manage to create two-word sentences at age 18-24 months and the other at age 30-36 months. Regardless of age when they create sentences appears to be said that this process takes place among all children in the same way subject to the same nomocracy $[4, \mathrm{p} .316]$. 


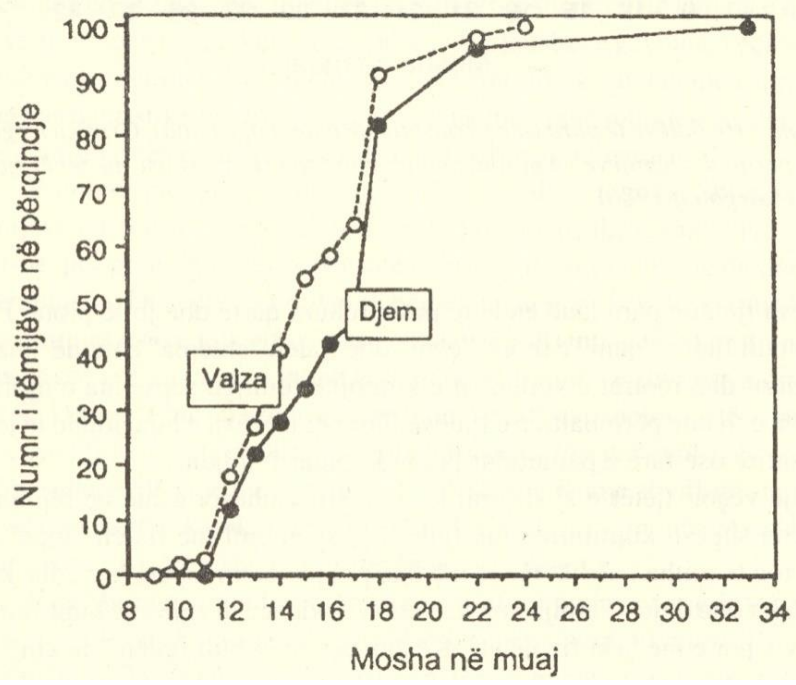

In this process the girls present a more rapid development than boys. With sentences or double word expressions, the child can be expressed in more differentiated than isolated words. He can communicate that a person or object is present or not, you can make the connection of actions and persons with their location and can express their desires and goals.

L. Gleitman in 1986 [8], supported the idea that children learn these two word categories almost separately from each other. R.Brown (1973) states for this stage of language development:

"... In the first phase the child is acting as the main elements of the sentence were optional and it doesn't seem that occurs due to a limited sentences complexity. In the second phase and beyond it acts as grammatical morpheme were optional ... He doesn't use what is called linguistically mandatory. This makes me think that the child expects to be understood when it does not produce any intelligible words. In fact, we discovered that he usually takes so as long as he is available at home, in the family environment or with relatives who know his history and trends. It can be said therefore that the first phase is well-adjusted for its communication ... but that would fail in other environments less familiar. This shows that the largest dimension of language development is to learn to express always and immediately some things like move, number, time ..." ".

Double word phase expressions also is called as telegraphic [9]. For the reason that the lack of maid words makes it look, more like a telegram. The child speaks more lexical words than grammar words, when noticed the lack of grammatical morpheme. Another linguist, Lois Bloom, regarded as a forerunner of the modern study of language development childlike, conducted an extensive study on the manner in which the nature of children's conversations modified during the second year of life. 
Conversations were initially analyzed for four children with three different ages, when they were 21 months and produced for more expressions of a single word, then at the age of 25 months, during which more expressions using both words and at the end when they were 3 years and 6 months, when expressed by phrases of 3 or 4 words. At what age children are able to rely on what others have said and carry the argument of the conversation? In other words, in what age most children observe the relationship? It is interesting to notice that in the phrase of producing single words, phrases that continue the argument of conversation are in higher number than those who turn.

At the conclusion of this material should emphasize that children can be helped in acquiring the language and the formation of linguistic general, thanks to many factors, among which these didactic books, which we tried to reflect increasingly harvested from mouth of the kids of preschool age. Our subjects conclude on the level and ability, as follows:

- Recognition newly special lexeme;

- Conversion of words from passive to active status;

- Enrichment of lexical input, taken as a whole.

- In addition lexematic case appears to become "construction" material for simple sentences; which the subjects begin to use according to communicative situations.

It's the moment to suggest that linguistic care development and lexical acquisition of these ages, depend in the first instance by the permanent presence of the educator as well as keeping the same level - increase of- the necessary requirements to keep the child in the position of self abilities to ourselves to the enrichment of vocabulary, up to his expectations, which is materialized and concrete in the structure of semantically related sentence.

\section{Bibliography}

[1] Brown, R., \& Fraser, C. (1963). The Acquisition of Syntax. In C. N. Cofer \& B. S. Musgrave (Eds.), McGraw-Hill series in psychology. Verbal behavior and learning: Problems and processes (p. 158-209).

[2] Brown, R., 1973. A First Language. Harvard University Press.

[3] CROMER, R.F. (1986), Language Acquisition: The State of the Art. Edited by Wanner \& Lila R. Gleitman. British Journal of Developmental Psychology, 4: 301-304.

[4] David, M., 1998. 2 À 6 Ans(Albanian Translated Version by Flutura 0.). Paris: Dunod, p.65.

[5] Largo, R., 2000. Babyjahre(Albanian Translated Version by Migena B.)). München: R. Piper.

[6] Lois, B. 1998. Language Development and Emotional expression. American Academy of Pediatrics, vol. 5. 
[7] Miller, Wick, and Susan Ervin. 1964. "The Development of Grammar in Child Language." Monographs of the Society for Research in Child Development, vol. 29, no. 1, pp. 9-34. JSTOR, www.jstor.org/stable/1165752.

[8] Shatz, M., 1998. Diario Dei Primi Passi. Bologna: Il mulino, p.95.

[9] Topalli, T., 2011. Gjuhësi Teksti. Shkodër: Univ. i Shkodrës "Luigj Gurakuqi", Inst. i Studimeve Albanologjike, p.107. 